\title{
A naturalização da identidade social precarizada na indústria do alumínio primário paraense
}

ATTILA MAGNO E SILVA BARBOSA"

Resumo

O objetivo deste trabalho é analisar em que medida o processo de terceirização em uma indústria de alumínio primário no município de Barcarena, no estado do Pará, produz diferenciações nas identidades sociais dos trabalhadores diretos e dos terceirizados. Como se sabe, os terceirizados possuem estatuto diferenciado no espaço de trabalho, o que os exclui da rede de benefícios oferecida pelas empresas. Nesse sentido, a sociedade passa a conviver não apenas com a fragilidade presente na relação salarial, mas também com o desmoronamento dos princípios reguladores da sociabilidade entre os trabalhadores. A hipótese levantada é a de que os estatutos mais precários que fundamentam a condição dos terceirizados se estendem por toda a constituição da vida social destes e lhes confere uma identidade social distinta. Foram realizadas 15 entrevistas com cada grupo de trabalhadores e duas entrevistas com dirigentes sindicais, também analisamos o acordo coletivo dos trabalhadores diretos com a empresa e os relatórios anuais desta desde o ano de 2003.

Palavras-chave: Produção flexível. Terceirização. Precarização. Identidade social. Albras S.A

\footnotetext{
* Mestre em Antropologia Social pela UFPA e Doutorando em Sociologia da UFSCar.
} 


\section{Introdução}

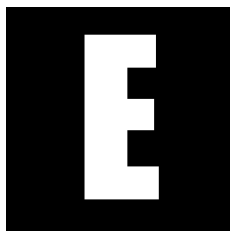

m agosto de 2006 a professora Helena Hirata ministrou uma palestra na Universidade Federal da São Carlos na qual ela fez uma análise comparativa sobre o desemprego no Brasil, França e Japão. Entre as coisas ditas, uma em especial chamou-nos atenção devido à reação de espanto protagonizada pela maioria da audiência ante ao fato relatado, qual seja: uma determinada pesquisadora de relações de trabalho na França, ao prestar assessoria ao Ministério do Trabalho francês, sugeriu que fossem tiradas das publicações governamentais a nomenclatura "trabalho precário" e em seu lugar fossem colocadas "novas formas de emprego".

Momentos antes ela havia feito referência às condições precárias e estressantes que jovens trabalhadores da área de comércio-exterior do aeroporto de Tóquio se sujeitavam para manter seus empregos. Em uma entrevista realizada com um desses jovens lhe foi revelado que, após pouco mais de um ano de trabalho, ele não suportou o ritmo imposto e pediu demissão. Como sabemos, a dificuldade de encontrar o primeiro emprego acaba levando os mais jovens a se submeter a tais situações. Por outro lado, é preciso considerar que, em uma sociedade onde o individuo é avaliado pela sua capacidade de cumprir metas, o ato do referido jovem se não o condenou para empregos futuros, pelo menos não será o seu melhor cartão de visitas. Dizemos isto, pois não aguentar o "tranco" não "pega bem" para um aspirante a "colaborador interno" de uma empresa flexível, mesmo que Ihe seja oferecido apenas uma contraprestação salarial e quiçá um punhado de penduricalhos travestidos de seguridade social.

Os discursos que tentam legitimar essa lógica tendem a criar toda uma simbologia de valorização dos comportamentos de risco a partir de uma racionalidade econômica que tenta se impor como única alternativa 
viável ao colapso do Estado Providência. Alguém poderia dizer que isto não passa de mais um simples discurso ideológico capitalista. Concordaríamos com esta interpretação, não fosse o fato de não estarmos diante de meras operações cognitivas de falseamento da realidade, mas sim de uma homologia entre a dimensão simbólica produzida por esses discursos e a ordem social configurada pelas práticas públicas e privadas da flexibilização. Em uma sociologia inspirada em Bourdieu (2002) diríamos que estamos diante de uma sociodicéia, isto é, uma narrativa que tem por função justificar a sociedade tal como ela é. Não deixa de ser ideologia, pois contribui para a corroboração das relações materiais dominantes, mas enquanto narrativa, pressupõe, como advoga Bourdieu (1998a), o que Durkheim chamou de conformismo lógico, isto é, uma concepção relativamente homogênea sobre as dimensões da vida social que tem como objetivo estabelecer uma ordem gnosiológica, um sentido imediato ao modo como o mundo social se apresenta estruturado. Desta feita, entendemos que a assimilação por parte dos trabalhadores do discurso da responsabilização dos indivíduos pela permanência ou não em uma determinada condição de existência material confere legitimidade ao poder simbólico do capital em tempos de flexibilização.

Ao nomear o trabalho precário como nova forma de emprego, a este discurso basta minar as resistências no campo político e gradativamente imiscuir-se na socialização das gerações futuras. Assim, essa incorporação tende a criar um horizonte de valores não mais alicerçados naqueles que deram sentido ao Estado Providência. Esse processo, como se sabe, já está em andamento, a sua maior evidência é a naturalização da postura do indivíduo como empreendedor de si mesmo. Porém, mesmo que na atualidade tal situação continue ganhando força, é preciso lembrar que ela não deixa de criar tensões e resistências. 
Como qualquer discurso, o da flexibilização também é potencialmente produtor de realidade, e em tempos de produção flexível, a terceirização se apresenta como uma das principais estratégias de organização do trabalho, entendida nesta matriz apenas como uma modalidade de relação técnica, como mera solução para situações de rigidez na relação entre capital e trabalho, tanto na esfera da gestão da mão de obra como na esfera jurídica. No entanto, reduzi-la somente a isto, é perder de vista o fato de ser o trabalho uma esfera fundamental de sociabilidade e de construção de identidades sociais. Por essa razão, entendemos ser possível verificar na interação entre trabalhadores diretos e terceirizados a existência de diferenciações que não apenas destitui o segundo grupo de uma rede de proteção social, mas também dificulta ou até mesmo elimina a possibilidade de inserção em determinadas esferas de sociabilidade. Nesse sentido, entendemos ser possível verificar entre esses dois grupos a existência de uma figuração entre estabelecidos e outsiders (ELIAS; SCOTSON, 2000) que se encontra fundamentada em duas situações que desprivilegiam os trabalhadores terceirizados, quais sejam: 1) a destituição do acesso à rede de proteção social oportunizada por uma grande empresa e, 2) a inserção social com um status diferenciado nas esferas de sociabilidade internas e externas ligadas à empresa. Este artigo se baseia no caso dos trabalhadores diretos e terceirizados da Albras S.A. ${ }^{1}$, empresa localizada no município de Barcarena, no estado do Pará, maior produtora individual de alumínio primário nacional e $8^{\underline{a}}$ do mundo.

A hipótese aqui levantada é a de que os estatutos mais precários que fundamentam a condição dos terceirizados não se encerram em uma relação técnica, eles se estendem por toda a constituição da vida social destes na região próxima ao município de Barcarena. Em outras palavras,

1 Empresa de capital fechado com 51\% de capital da CVRD - Companhia Vale do Rio Doce S/A e 49\% da NAAC - Nippon Amazon Aluminium Company Ltd, consórcio de 17 empresas japonesas, entre trading companies, bancos, consumidoras e produtoras de alumínio, e o Japan Bank for Internacional Cooperation. 
a condição de terceirizado conduz a uma vulnerabilidade social que se manifesta não apenas objetivamente, devido ao não acesso à rede de proteção social contida nos contratos de trabalho mais estáveis, mas também subjetivamente, pois tem conduzido a uma baixa autoestima social.

A pesquisa que deu origem a este trabalho baseou-se em entrevistas com quinze trabalhadores da Albras, quinze trabalhadores terceirizados, dois dirigentes do Sindicato dos Metalúrgicos de Barcarena (SIMEB) e um diretor da Associação dos empregados do complexo industrial Albras/Alunorte (ABAN). Também utilizamos como fontes de informações, o acordo coletivo de trabalho entre o sindicato e a empresa, o estatuto da Aban e os relatórios da administração da Albras de 2003, 2004, 2005, 2006 e 2007.

\section{Produção flexível e fragmentação da classe trabalhadora}

Piore e Sabel, autores do livro The second industrial divide, são tidos como os pioneiros na proposição do termo "especialização flexível" para designar o "novo modelo de produção" surgido como alternativa à rigidez do modelo taylorista-fordista pós-crise de 1973. Segundo esses autores estaríamos diante de um novo paradigma industrial, já que este "inverte agudamente os princípios tecnológicos estabelecidos e conduz de volta àqueles métodos artesanais de produção que ficaram para trás na primeira fronteira industrial" (1984, p. 6). Esse novo paradigma se caracterizaria pelo maior dinamismo e pelo menor grau de verticalização em sua estrutura de poder. Considerando o caso da "Terceira Itália", eles definiram esses sistemas mais flexíveis de produção e de organização do trabalho como uma "estratégia de inovação permanente: adaptação à mudança incessante, em vez de esforço para controlá-la" (1984, p. 17).

Contudo, apesar do pioneirismo, o esquema de análise de Piore e Sabel tem sido duramente criticado por vários autores, entre os quais 
Harvey (2002) e Antunes (1999; 2005), que argumentam ter este esquema analítico três pontos fundamentais de limitação: a) caracterização da flexibilização somente como variável positiva; b) generalização abusiva de casos localizados (Japão e "Terceira Itália"); c) não consideração dos efeitos sociais deletérios gerados pelo "modelo", como, por exemplo: aumento do desemprego, utilização precária de mão-de-obra, baixos salários e aumento do controle sobre a força de trabalho.

As críticas feitas à perspectiva de Piore e Sabel, embora pertinentes, não podem negligenciar o fato de que a emergência, a partir dos casos do toyotismo e da "Terceira Itália", de novos modelos organizacionais baseados na cooperação e na ação conjunta de micro e pequenas empresas diferencia-se substancialmente dos modelos organizacionais das empresas altamente burocratizadas que caracterizavam o período taylorista-fordista. Tal configuração é denominada por Castells (2002) como modelo de empresa em rede.

A vertente japonesa desse modelo empresarial se caracteriza, segundo Coriat (1994), pela descentralização das atividades de grandes empresas em unidades quase autônomas e do estabelecimento de alianças estratégicas com micro e pequenas empresas, pressupondo desta feita uma lógica de cooperação e autonomia ligada a uma divisão equilibrada do trabalho entre empresas que compõem a rede.

A emergência deste modelo empresarial reticular ocorreu devido à abertura de mercados internacionais oportunizada pela saturação dos mercados domésticos de consumo decorrente da progressiva redução da eficácia das políticas econômicas keynesianas de estímulo à demanda que estavam atreladas ao modelo fordista. Aliado a isto, a inovação tecnológica oportunizada pelo uso da robótica e da microinformática alimentou a passagem das economias de escala fordista para um outro modelo industrial, o da especialização flexível. Nesse sentido, as unidades produtivas 
de pequeno porte, devido às tecnologias informáticas e a certo nível de especialização possuem uma capacidade adaptação mais flexível ante as evoluções qualitativas e quantitativas de uma demanda cada vez mais imprevisível (CORIAT, 1994; COCCO, 1999).

Não por outro motivo, um autor como Castells (2002) dizer que, em decorrência das condições de imprevisibilidade introduzidas pela rápida transformação econômica e tecnológica, as grandes empresas se viram impelidas a mudar seu modelo organizacional para adaptarem-se à nova configuração do capitalismo. Para Castells: “a principal mudança pode ser caracterizada como a mudança de burocracias verticais para a empresa horizontal" (p. 221), sendo que esta é definida como "uma rede dinâmica e estrategicamente planejada de unidades autoprogramadas e autocomandadas com base na descentralização, participação e coordenação" (p. 223). No entanto, as redes de subcontratação inerentes a este modelo não têm conduzido, na maioria dos casos, a uma ruptura efetiva com o modelo taylorista-fordista, exemplo disto é quando um conjunto de pequenas e médias empresas está essencialmente vinculado a uma empresa central ou a algumas empresas centrais.

A divisão desigual do trabalho entre empresas pode resultar em relações de dependência e forte segmentação no que se refere às formas organizacionais e a qualificação dos recursos humanos (KOVÁCS, 2001; CASTELLS, 2002). Até porque, no contexto da produção flexível a terceirização se apresenta como uma estratégia chave de redução de custos e de flexibilixação da gestão da produção e do trabalho. Muito embora, não devamos esquecer que em alguns setores industriais a ocorrência da subcontratação antecede o advento do fordismo, exemplo disto são as indústrias de confecções e de calçados que se caracterizam pela utilização de trabalho intensivo desde o século XIX. Entretanto, hoje se testemunha a generalização dessa lógica, inclusive para indústrias de capital intensivo, 
como o são as indústrias metalúrgicas, que também já vinham praticando a subcontratação, mas antes restrita às atividades consideradas menos chave da atividade empresarial.

Por isso, pensar a terceirização é tê-la como um dos principais fatores de intensificação do processo de fragmentação da classe trabalhadora. Deste modo, devemos entendê-la como um fenômeno social que se disseminou a partir das transformações ocorridas no mundo produtivo póscrise econômica iniciada em 1973. Isto porque, desde esse período, a reestruturação produtiva tem sido imposta como receituário adequado para o virtual esgotamento do taylorismo-fordismo como modo de regulação econômica e de organização produtiva. Assim, experiências particulares tidas como modelos mais flexíveis de produção e de relações de trabalho, como os casos do "toyotismo" no Japão e da rede de micro e pequenas empresas na chamada "Terceira Itália" (nordeste italiano), passaram a ser entendidas como respostas à rigidez dos processos produtivos e das redes de proteção social do trabalho que caracterizaram o mundo capitalista nos vinte e cinco anos anteriores à crise.

A difusão desses modelos é justificada com base no argumento de que é necessário agir de forma mais eficiente em um contexto de aumento da competitividade global. Deste modo, valores como desburocratização, inovação, diversificação, valorização de recursos humanos como meio de aumentar a competitividade e desmanche do Estado-providência são tidos como imprescindíveis para a sobrevivência empresarial na economia atual (KOVÁCS, 2001). Nesse sentido, não é por acaso que a flexibilização do trabalho tenha como fundamentos: os princípios da responsabilidade, qualificação e participação dos trabalhadores. O objetivo é estabelecer um modelo de cooperação baseado em um novo trabalhador coletivo, diferente daquele que caracterizou o período fordista. Agora, a organização do trabalho não mais é norteada pela rigidez dos postos de trabalho, 
mas sim pela mobilidade e pela versatilidade de trabalhadores com altos níveis de qualificação e independência, configurando assim, a exigência pela polivalência (ZARIFIAN, 1993).

Nos modelos de produção flexível, a fábrica enxuta é o ideal a ser alcançado; ideal este que se busca alcançar por intermédio da remoção das camadas consideradas desnecessárias de trabalho vivo. Sobre esse assunto Taiichi Ohno (1997), engenheiro responsável pela criação do modelo de produção da Toyota, é bastante claro: "na Toyota, o conceito de economia é indissociável da busca de redução de efetivos e de redução de custos". A fábrica deve ser organizada para trabalhar com um número mínimo de operários multifuncionais. No Toyotismo, fábrica eficiente é sinônimo de fábrica mínima, isto é, de fábrica que com um número menor de trabalhadores consegue aumentar os níveis de produtividade. Situação bem diferente do modelo taylorista-fordista, em que, como salienta Antunes (1999), a pujança de uma empresa era mensurada pelo número de operários que nela trabalhavam. Por isso, não é à toa que a experiência japonesa da Toyota tem na terceirização uma prática inerente ao seu modelo organizacional de fábrica enxuta.

$\mathrm{Na}$ análise feita por Coriat (1994), o modelo Toyota inverte as regras tradicionais da lógica fordista, na qual a parcelização das tarefas e a separação entre concepção e execução destituiam os trabalhadores de pensar o processo de trabalho a qual estavam sujeitos. Tal mudança teria sido possível devido ao estabelecimento paralelo do desenrolar dos fluxos reais de produção e de um fluxo de informação que vai de jusante à montante da cadeia produtiva; o que torna a produção mais enxuta, já que a produção ocorre no ritmo dos pedidos realizados. Desta feita, este sistema, denominado just in time, não preconiza a produção em larga escala, mas sim em lotes de séries menores determinados pelo fluxo da demanda. A partir do final da década de 1960, com o desenvolvimento da telemática e da 
robótica, diminui-se ainda mais a necessidade de força de trabalho e, por conseguinte, o processo de trabalho passou a ser pensado e realizado em equipes de trabalhadores mais diretamente ligados ao processo produtivo.

Para Antunes (2005), as empresas que se inspiram no modelo japonês promovem um "envolvimento cooptado" que permite a apropriação do saber e do fazer dos trabalhadores, fazendo-os pensar e agir em consonância com os interesses do capital. Isto é facilmente confirmado quando se considera que nos novos discursos gerenciais a substituição do termo funcionário pelo termo "colaborador interno" tem se apresentado como uma estratégia de redefinição de significados. Tal operação de redefinição da condição do trabalhador está inscrita no conjunto de estratégias gerenciais que objetivam transformar a subjetividade do trabalhador no que concerne ao modo como ele percebe sua relação com a empresa, ou se preferirmos, a relação entre capital e trabalho.

Entretanto, para que essa redefinição de significados pareça minimamente verossímil aos olhos dos trabalhadores, ela precisa sair da simples esfera discursiva e passar a ser vivenciada no espaço fabril onde o processo de trabalho ocorre. Caso contrário, o sentido do envolvimento que se busca obter fica seriamente comprometido, pois o seu conteúdo simbólico se esvai na experiência das práticas cotidianas e consequentemente a opacidade da situação se faz sentida na discrepância entre o que versam as prescrições discursivas gerenciais e o que efetivamente operacionalizam as práticas gerenciais.

Atualmente a fábrica flexível é tida como condição básica de sobrevivência empresarial devido à saturação progressiva da norma de consumo fordista que originou a demanda de consumo por bens duráveis e ao mesmo tempo flutuante e diversificada. Como consequência, mercados mais incertos e heterogêneos surgiram, o que gerou uma contradição direta com a rigidez e a onerosidade do modelo de produção taylorista-fordista, que só 
conseguia amortizar rapidamente os investimentos em equipamentos por meio de uma produção em massa contínua. Assim, o aumento da variabilidade da demanda exigiu uma maior flexibilidade no processo produtivo via introdução de meios de trabalho aptos para o ajuste da capacidade produtiva ao volume e à composição da demanda (BIHR, 1999).

Do ponto de vista empresarial é correto pensar que a mudança de um modelo de produção mais rígido para um mais flexível traz mais benefícios do que malefícios. Por outro lado, do ponto de vista social, devido ao modelo de especialização flexível que se materializa na fábrica enxuta e se alimenta de constantes inovações tecnológicas, o desemprego estrutural se apresenta como uma externalidade negativa. Todavia, Castel (2003) nos chama atenção para o fato do desemprego ser apenas a manifestação mais visível de uma profunda transformação do emprego, pois a precarização do trabalho seria outra característica desta situação, em suas palavras, "menos espetacular, porém mais importante". Isto se apresenta na perda gradativa de hegemonia do contrato de trabalho por tempo indeterminado que institui uma sociedade salarial onde os trabalhadores podiam vislumbrar certa estabilidade em sua vida por conta da rede de proteções sociais existentes.

O avanço da flexibilização instaura o que Castel (2003) chama de nova questão social, na qual a precarização do trabalho torna-se o principal fator da crescente pauperização da classe trabalhadora. Sob o ângulo do trabalho três pontos de cristalização emergem: a) desestabilização dos estáveis em decorrência da redução dos contratos por tempo indeterminado; b) a instalação da precariedade, por conta da condição de "interino permanente"; c) e o déficit de lugares ocupáveis na estrutura social, entendido aqui pelas posições às quais se associa uma utilidade social e um reconhecimento público. Assim, para categorias cada vez mais numerosas da população ativa a identidade pelo trabalho estaria perdida; caracterizando um processo de desfiliação, isto é, a perda dos suportes sociais 
que sustentam a condição de cidadania em sociedades democráticas e o desengajamento material e simbólico dos indivíduos diante dos vínculos que os ligam à coletividade.

No período taylorista-fordista, apesar das heterogeneidades e desigualdades existentes entre a classe trabalhadora, era possível notar a predominância de certa tendência à homogeneização decorrente de uma "estratégia de integração" do proletariado ao modo de vida capitalista propiciado pelo "compromisso fordista". A partir do final da década de 1970 uma fragmentação crescente do proletariado ocidental estaria conduzindo-o a uma paralisação enquanto força social. A transformação da relação salarial na era da produção flexível configura novas imagens proletárias, sendo que três grandes conjuntos emergem: a) os proletários estáveis com garantias, uma reminiscência do período taylorista-fordista; b) os proletários excluídos do trabalho, aqueles condenados ao desemprego e à dependência da seguridade social e; c) uma massa flutuante de trabalhadores instáveis, na qual se incluem os trabalhadores em tempo parcial, os temporários, os informais e os terceirizados. Essas diferentes imagens dificultam a construção de uma identidade comum da classe trabalhadora (BIHR,1999).

Não por outros motivos que autores como Offe (1989), Gorz (1982) e Habermas (1987) advogam em favor da tese da perda de centralidade do trabalho como categoria fundamental. Alegam que a instabilidade na construção a partir da esfera do trabalho de um ambiente de vida social como uma unidade subjetiva estaria se tornando cada vez mais inútil em

2 Estratégia inscrita no cerne do New Deal, isto é, na série de programas implementadas entre os anos de 1933-1937, pelo governo do então presidente dos Estados Unidos F. D. Roosevelt (1882-1945), que tinham como fundamento as ideias intervencionistas do economista inglês J. M. Keynes (1983-1946) e que visavam recuperar e reformar a economia norte-americana e assistir aos prejudicados pela Grande Depressão pós crise de 1929. Na Europa foi promovido por meio do Estado do bem-estar social. As suas características principais foram: a negociação coletiva, a uniformização da condição jurídica dos diferentes trabalhadores e a efetividade do emprego. Do ponto de vista político visava o estabelecimento de uma "parceria antagônica" entre o capital e o trabalho, conduzindo os trabalhadores, de um modo geral, a um tipo de atuação política norteada para o atendimento de demandas econômico-corporativas. 
decorrência do tempo que os indivíduos a ela despendem. Ou seja, a identidade social e pessoal pela via do trabalho estaria perdendo força no atual contexto do capitalismo. A ocorrência disto seria uma decorrência das inovações tecnológicas e do fato da biografia individual dos trabaIhadores não necessariamente ter na formação profissional a realização de uma carreira a ela condizente. Para esses autores a esfera do trabalho perde sua posição de categoria central na sociedade e cede lugar àquilo que Habermas denomina de "esfera comunicativa", onde as identidades se constroem mais fortemente a partir do "mundo da vida". Isto é, a partir de um conjunto de atividades que se realiza na interação intersubjetiva do dia a dia e não apenas na esfera institucional do trabalho.

Todavia, é preciso lembrar que a flexibilização e/ou a redução dos direitos sociais ligados à condição de assalariamento nas sociedades capitalistas contemporâneas tem conduzido a uma situação de insegurança social que não apenas se restringe ao mundo do trabalho, mas afeta todo o sistema de vida social. Diante da persistência desta situação, a derrocada dos princípios reguladores e fundadores de coesão social se tornam inevitáveis. Para nós, é exatamente essa condição de insegurança que se apresenta como fator decisivo na construção de identidades sociais distintas entre trabalhadores diretos e terceirizados, tanto nos ambientes internos quanto externos das instalações fabris.

\section{A identidade social precarizada na indústria do alumínio primário paraense}

A reorganização da econômica capitalista pós-crise dos oil shocks do início da década de 1970 institui uma nova divisão social do trabalho, na qual uma de suas marcas se tornou a relocalização de atividades industriais dos países industrializados que tradicionalmente detinham a pro- 
dução manufatureira para países semi-industrializados ou de industrialização recente. Dentro deste novo cenário, o setor industrial do alumínio primário sofreu consideráveis mudanças. Um exemplo disto é o caso da indústria japonesa, que devido ao virtual fechamento de sua capacidade produtiva passou a incentivar o desenvolvimento de fontes alternativas de abastecimento de alumínio primário em países com abundância de energia barata e de reservas de bauxita, como é o caso do Brasil, mais especificamente o Estado do Pará3 (TARSITANO NETO, 1995).

Nesse sentido, a instalação de uma cadeia produtiva de alumínio primário no Estado do Pará, constituída pela exploração da bauxita pela Mineração Rio do Norte S.A, pela Alunorte S.A produtora de alumina e pela Albras S.A produtora de alumino primário, se apresenta como um exemplo desta reorganização econômica, aqui entendida como resultado local de um processo de reestruturação que gera diversas formas coexistentes de reorganização produtiva e espacial, tanto em nível regional, como global.

A Albras, mais especificamente, tem sido locus de diversos estudos no Estado do Pará, isto se deve ao protagonismo que ela exerce no cenário empresarial paraense e aos impactos socioeconômicos que produz no entorno do município de Barcarena. Como objeto de estudo, ela já foi analisada a partir de sua constituição enquanto filial-atêlie voltada para o fornecimento de alumínio primário para verticalização produtiva no

3 O Pará tem instalado em seu território a maior produtora de bauxita do país e uma das três maiores do mundo, a Mineração Rio do Norte - MRN, localizada em Porto de Trombetas no município de Oriximiná, também coligada a CVRD, com capacidade instalada de 16,3 milhões de toneladas anuais de minério (Empresa de Pesquisa Energética, 2005). A bauxita é matéria prima básica para a produção da alumina, que junto com a energia elétrica, produzida pela usina hidrelétrica de Tucuruí - segunda maior usina do país, localizada no rio Tocantins, com capacidade instalada de 4.245 MW, até o final de 2002 - são as matérias primas básicas para a produção do alumínio primário na forma de lingotes. Para se ter uma ideia, a Albras por se tratar de uma indústria eletrointensiva é hoje a maior consumidora individual de energia do Brasil, respondendo por $1,5 \%$ de toda a demanda nacional (PINTO, www.adital.com.br). Isto representa o mesmo consumo de Belém e Manaus juntas, as duas maiores cidades da região norte, que respectivamente possuem 1.408 .847 e 1.612.475 habitantes (IBGE, 2007). 
Japão; situação esta que decorreu da relação estabelecida entre o Estado brasileiro, após o II PND - Plano Nacional de Desenvolvimento (19751979) e o capital transnacional. Nessa linha, a Albras é entendida como uma decorrência da exigência de uma nova configuração da divisão social do trabalho na cadeia produtiva do alumínio (LÔBO, 1996). Em um outro estudo (CARMO, 2000), suas práticas de gestão do trabalho baseadas em técnicas de controle de qualidade e de trabalho em equipe foram estudadas no sentido de entender o modo como se processa a adesão e as resistências da força de trabalho aos objetivos da empresa, assim como, de que maneira a força de trabalho percebe e internaliza essas técnicas.

Seguindo uma abordagem distinta, o que nos interessa aqui é analisar como o processo de terceirização na Albras produz diferenciações na construção da identidade social dos trabalhadores terceirizados. Pois entendemos que o trabalho deve ser encarado não apenas como uma relação técnica, mas também como um suporte privilegiado de inscrição na estrutura social. Até porque, no contexto taylorista-fordista, o assalariamento e a conseguinte participação nas redes de sociabilidade e de proteção social, se nunca estiveram disponíveis para maioria da classe trabalhadora no Brasil, pelo menos se apresentavam como um horizonte almejável de constituição de uma rede de proteção social pela via do trabalho.

Antes de entrarmos no caso da Albras, mas ainda lançando os olhos para a realidade da cadeia produtiva do alumínio no Pará, temos um outro estudo, realizado por Trindade (2001) sobre a terceirização na empresa Mineração Rio do Norte S.A (MRN), que é importante ser relatado. No caso da MRN, desde 1986 as atividades de manutenção da infraestrutura comunitária de Trombetas já eram realizadas por empresas subcontratadas. A partir de 1991, por conta do início da reestruturação na empresa é que a terceirização foi se estendendo paulatinamente às atividades concernentes ao processo produtivo. Segundo Trindade, além 
do enxugamento do corpo funcional como fator de maior controle da força de trabalho vinculada ao núcleo estratégico do processo produtivo, a terceirização produziu um efeito dispersivo sobre o coletivo de trabalhadores, pois os espalhou em uma miríade de empresas de diversos portes, principalmente pequenas e médias, contribuindo assim para uma fragilização da solidariedade operária.

No caso da Albras, a adoção desse modelo organizacional teve início em 1989 com a implementação dos Círculos de Controle de Qualidade. O objetivo era dinamizar as relações de trabalho a partir de um envolvimento mais participativo dos funcionários no processo de produtivo e assim repassar para terceiros uma série de atividades. O princípio norteador foi a descentralização de atividades que poderiam ser realizadas por pequenas e médias empresas, liberando a empresa para atividades prioritárias (CASTRO, 1998).

Tanto a MRN quanto a Albras são exemplos do que Druck (1999) afirma sobre ser a terceirização um processo adjacente ao programa de qualidade total, pois responde pela redução de custos e pelo reordenamento das tarefas. Ambos os casos confirmam a tese da íntima ligação entre a implementação de programas de qualidade total e a terceirização. Por isso, autores como Leite (1994), Mattoso (1995) e Ruas (1994) defendem que, no Brasil, os diferentes processos de adaptação empresarial às novas exigências de competitividade assumem um caráter de modernização conservadora. Na maioria dos casos, a adoção desses processos não corresponde a mudanças efetivas nas relações de trabalho. Até porque, nos casos japonês e italiano, a terceirização se apresenta, com certa frequência, como uma oportunidade de transferência de conhecimentos tecnológicos e organizacionais entre as empresas que integram uma rede empresarial.

No caso das indústrias de alumínio primário, por serem indústrias de processo semi-contínuo, a terceirização se diferencia das indústrias de série 
devido a não existência em suas cadeias produtivas da mesma possibilidade de adaptabilidade e flexibilização de processos e produtos. Por isso, é dada uma maior atenção às funções de controle, comando e correção de processos. Nestas, a flexibilização da produção basicamente consiste em controle de qualidade, adoção de novos modelos de gestão da produção e flexibilização das relações de trabalho via terceirização (CASTRO, 1998).

Visando compreender a figuração social existente entre trabalhadores diretos e terceirizados da Albras, é importante dizer que a instalação do complexo industrial Albras-Alunorte exigiu a construção de uma company town ${ }^{4}$, um núcleo residencial chamado Vila dos Cabanos ${ }^{5}$, custeado e construído pelo Governo Federal seguindo as diretrizes do II PND (1974-1979) e a ideia de pólo de desenvolvimento do III PDA - Plano de Desenvolvimento da Amazônia (1980-1985). Todavia, apesar do núcleo ter sido planejado à luz do conceito de "cidade aberta", ele apresenta características de uma vila "fechada", como, por exemplo, homogeneidade e segregação (RODRIGUES, 1998). O projeto urbanístico e implantação foram realizados pela Codebar - Companhia de Desenvolvimento de Barcarena, órgão vinculado ao Governo Federal, que detém a titularidade das terras e comercializa os terrenos urbanos, além de monitorar a obediência ao plano urbanístico.

A Vila dos Cabanos foi construída para servir de moradia e atender as necessidades dos trabalhadores do complexo e demais empresas que se instalassem na microrregião de Barcarena. Para tal, foi disponibilizada uma rede de infraestrutura com sistema de esgoto, água, energia elétrica, escolas, hospitais e clube. As disparidades infraestruturais em relação ao restante do município de Barcarena são visíveis, até mesmo porque durante muito tempo a administração do núcleo coube ao complexo Albras/ Alunorte. Porém, esse quadro tem mudado drasticamente devido à de-

4 O termo Company Town corresponde a uma denominação inglesa que designa toda e qualquer formação habitacional de apoio, de caráter autárquico, ligada a qualquer tipo de empresa ou companhia.

5 Localizado a $15 \mathrm{~km}$ da sede do município de Barcarena. 
teriorização da infraestrutura urbana e à expansão de áreas de ocupação espontânea, pois, como demonstra Nahum:

Com as transformações nas políticas de desenvolvimento regional e os planos de privatizações dos governos federal e estaduais, o munícipio de Barcarena e, por consiguinte a Vila dos Cabanos deixa de ser preocupação e responsabilidade das empresas. A privatização da Companhia Vale do Rio Doce (CVRD) e as reformas na alocação do fundo público influenciam as políticas desenvolvidas pela Albras/Alunorte. As empresas, gradativamente, estão transfrindo para a responsabilidade municipal a manutenção e o provimento de serviços e infra-estrutura que mantinha. No quadro legal a competência de responsabilidade foi redefinida, quando a Lei Orgânica Municipal transferiu praticamente todas as atribuições de controle, fiscalização e implementação para a prefeitura de Barcarena, que está progressivamente, assumindo a manutenção e ampliação dos serviços urbanos e de infra-estutura alocados no lugar (2006, p. 57).

Feita essa breve caracterização, entremos agora no caso específico da Albras. No dia 6 de julho de 1985, quando do início do funcionamento da primeira fase de sua planta industrial, ela tinha capacidade de produção nominal anual de 160.000 toneladas de lingotes de alumínio. Em 1991, com a partida da segunda fase, essa capacidade aumentou para 320.000 t/ano. Em outubro de 1993 foram concluídas melhorias tecnológicas que aumentaram sua capacidade nominal de produção para 345.000 t/ano. Em dezembro de 2001, devido a outra expansão em seu parque industrial, houve um aumento para 406.000 t/ano. Já em 2002 ela supera esse número e produz 407.726 t/ano, nos anos seguintes ocorreram sucessivos recordes de produção e em 2006, outro recorde, 455.561 t/ano. Todavia, o mais revelador foi ela ter conseguido tais números com médias anuais de 1.307 e 1.271 empregados diretos no final dos respectivos anos. Isto porque, no início dos anos 1990, quando a empresa gradativamente implementa técnicas de gestão inspiradas no modelo japonês, o número de empregados diretos 
era de 2.356. O importante, para fins desse trabalho, é que nos anos 2000 o aumento da produtividade vem ocorrendo com pequenas reduções na média do quadro funcional efetivo anual, nada comparável às reduções ocorridas na década anterior decorrentes de processos de reestruturação mais intensos, porém é algo que parece caracterizar uma tendência que caminha no sentido de se conseguir otimizar o ajuste entre seu quadro funcional e sua capacidade produtiva. Em outras palavras, tornar-se o mais enxuta possível. Vide o quadro abaixo.

Quadro 1. Produtividade lingote/empregado/ano na ALBRAS S.A (2001-2007)

\begin{tabular}{cccccccc}
\hline Itens/anos & 2001 & 2002 & 2003 & 2004 & 2005 & 2006 & 2007 \\
$\begin{array}{c}\text { Produção } \\
\text { Lingotes } \\
\text { (t) }\end{array}$ & 332.711 & 407.726 & 432.121 & 435.026 & 445.393 & 455.561 & 455.272 \\
$\begin{array}{c}\text { Média } \\
\text { Efetivo/ } \\
\text { Ano }\end{array}$ & 1.301 & 1.307 & 1.300 & 1.299 & 1.292 & 1.271 & 1.271 \\
$\begin{array}{c}\text { Produção/ } \\
\text { Empre- } \\
\text { gado }\end{array}$ & 255,7 & 312,0 & 332,4 & 334,9 & 344,7 & 358,4 & 358,2 \\
\hline
\end{tabular}

Fonte: Albras S.A (Relatórios da Administração 2003/2004/2005/2006/2007)

O quadro demonstra que de 2005 para 2006 ocorreu um aumento de produtividade de 3,97\% na relação lingote/empregado/ano, de 2004 para 2005 o aumento foi de 2,93\%, de 2003 para 2004 foi de 0.8\%, de 2002 para 2003 o aumento foi de 6,5\% e de 2001 para 2002 houve um aumento de $22 \%$, o mais significativo desse período devido à expansão da capacidade produtiva da empresa. Todavia, muito embora tenha havido uma ínfima queda de produtividade no ano de 2007, algo em torno de $0,1 \%$ na relação lingote/empregado/ano, isso ocorreu devido ao maior número de fornos que foram reformados no período ${ }^{6}$ e não a uma queda real de produtividade por

6143 fornos contra 77 fornos em 2006 (Fonte: Relatório Anual da Administração da Albras, 2007). 
empregado. Essa situação ilustra bem o fato de que, na Albras, otimização da produção, como em qualquer empresa que objetiva maximizar os ganhos de seus acionistas, significa produzir o máximo possível com o mínimo possível de trabalhadores diretos. Para tal, a empresa alia intensificação das responsabilidades dos seus funcionários no processo produtivo e incorporação de novas tecnologias à ampliação do uso de mão de obra terceirizada; o que a caracteriza como um exemplo de "fábrica enxuta".

Quanto ao caráter globalizado da empresa, isto é algo que não apenas decorre da composição do seu capital, 51\% CVRD e 49\% NAAC, mas também dos processos organizacionais ${ }^{7}$ por ela adotados, vide em sua cultura organizacional ter sido gradativamente impressa a marca do sistema TQC - Total Quality Control, inspirado no modelo de gerenciamento japonês, que foi sendo implementado a partir do ano de 1989 e incorporando-se ao cotidiano da fábrica no decorrer dos anos de 1990, culminando em 1996 com a expansão do programa CCQ - Círculo de Controle de Qualidade ${ }^{8}$ para toda a empresa. Esse modelo foi fundamental para o processo de "enxugamento" do número de empregados diretos da empresa, pois como demonstrou Carmo (2000), entre os seus princípios vitais se fez presente a otimização dos custos. Entretanto, segundo o testemunho de funcionários que trabalham na fábrica desde a segunda metade dos anos de 1980, a implementação de fato só ocorreu no final da década de 1990, pois no decorrer desta houve muita resistência à implementação dessas práticas organizacionais devido ao fato de muitos pensarem que elas não trariam mudanças efetivas na postura autoritária

7 A Albras é possuidora das certificações ISO 9001 - Sistema de Garantia de Qualidade, ISO 14001 - Controle Ambiental e do OHSAS 18001 Controle de Saúde e Segurança Ocupacional, e SA 8000, sistema de auditoria referente à Responsabilidade Social Empresarial baseado nas normas internacionais de direitos humanos e nas convenções da OIT - Organização Internacional do Trabalho.

8 No ano de 2006, dez anos após a implementação dos CCQs para toda a planta industrial, a Albras alcançou o número de 135 círculos e de 960 trabalhadores (circulistas) inscritos, o que representa uma adesão superior a $95 \%$ do efetivo operacional da empresa. 
do corpo gerencial da empresa. Isso muda após o episódio da privatização da CVRD, pois a partir daí os funcionários passaram a perceber que a empresa de fato começou a mudar esse estado de coisas, tendo inclusive demitido os gerentes que não se adaptaram ao novo modelo de gestão. Deste momento em diante, os trabalhadores mais antigos da Albras relatam que passaram a ter a sensação de "ausência de chefe" nas áreas, sensação corroborada pelos funcionários que entraram após as mudanças.

Considerando o caso da Albras, pode-se dizer que, apesar de certo nível de horizontalização, a empresa efetivamente não tem gerado rupturas significativas nos padrões tradicionais de relações de trabalho, isso ficaria evidente segundo Castro (1998), nos espaços de sociabilidade em Vila dos Cabanos, onde reside á maioria dos empregados da Albras. No entanto, apesar de todos os trabalhadores estarem em igualdade de condições no clube e no espaço do restaurante da empresa, é possível notar um seccionamento entre os funcionários, decorrente do lugar que estes ocupam na estrutura funcional da empresa.

Nesse ponto a terceirização tem "uma função de (re) hierarquizar, seccionando, de um lado, as empresas do sistema CVRD e, de outro, as empreiteiras, cujos salários são bem diferentes, ainda que estas sejam induzidas a familiarizar-se com os princípios de modernização e de gerenciamento de qualidade total" (CASTRO, 1998, p. 14).

No que diz respeito à constituição de um contexto propício para a figuração de identidades sociais distintas entre trabalhadores diretos e terceirizados que atuam no chão da fábrica foi possível constatar tanto nas falas dos funcionários da Albras quanto dos terceirizados, a existência de algumas situações que contribuem para isto:

a) Os trabalhadores da Albras possuem uma Associação chamada ABAN (Associação dos empregados da Albras e Alunorte), que entre outras coisas promove para seus associados cursos de teclado, violão, secretariado, 
manutenção de micro e de informática, o valor da mensalidade nesses cursos e de $\mathrm{R} \$ 40,00$ reais, para os não associados $\mathrm{R} \$ 90,00$. Também é disponibilizado um caminhão baú para viagens de até 25 associados toda semana para compras em supermercados de Belém, com taxa de $\mathrm{R} \$ 10,00$. Essa última situação tende a perder força devido à instalação de uma grande cadeia de supermercados na Vila dos Cabanos, mas aqui fazemos referência a ela, pois jamais foi acessível aos terceirizados;

b) No entorno da Vila dos Cabanos existem hoje cinco grandes ocupações espontâneas: Novo Horizonte, Jd. Cabano, Laranjal e Pioneiro e a mais recente Beira Rio. Nestas residem, diferentemente do núcleo urbano da Vila dos Cabanos, a mão de obra menos qualificada, que usualmente é utilizada pelas empresas que terceirizam serviços para a Albras. Assim com também mão de obra do Município de Abaetetuba, que fica a $53 \mathrm{~km}$ de Barcarena.

c) As portarias diferenciadas para os funcionários da empresa e para os terceirizados, sendo que desde 1996 os primeiros não são mais revistados, já os segundos continuam sendo. De acordo com o que nos foi relatado pelos terceirizados, toda vez que eles entram de carro ou com bolsas sempre são revistados, caso contrário ficam sem o credenciamento para entrar na fábrica. Da parte dos terceirizados entrevistados existe a percepção clara de que a empresa desconfia deles, por conta disto ela Ihes trata de modo diferenciado. Porém, os terceirizados revelam em suas falas certa resignação ante as normas internas da empresa, mesmo que as achem constrangedoras. Neste ponto, a opinião coincide com a dos funcionários da empresa entrevistados. Porém, no que concerne à percepção da existência de discriminação, os funcionários da Albras de um modo geral acham que não é essa a intenção da empresa, mas apenas promover a sua segurança patrimonial.

d) O Programa Bolsa Estágio, oportunizado aos filhos dos funcionários da empresa, no qual, caso abram vagas no decorrer do estágio lhes é dada 
preferência no processo de contratação. Exemplo disto são três funcionários diretos entrevistados com menos de dez anos na empresa que ingressaram por meio deste programa. Os outros dois nesse enquadramento temporal participaram de processos seletivos por indicação de parentes;

e) A criação do Programa Vida Saudável, em outubro de 2004, no qual a empresa disponibiliza para seus funcionários o acesso a um nutricionista, um psicólogo e um professor de educação física, assim como a uma academia de musculação no Cabana Clube. O programa visa disponibilizar assistência para questões ligadas ao sobrepeso no sentido de tentar evitar problemas cardíacos e de saúde, aumentando a qualidade de vida dos seus funcionários e consequentemente a produtividade. Esse programa, não só não é acessível aos terceirizados, como todos os que foram entrevistados revelaram desconhecê-lo;

f) Os eventos esportivos promovidos pela empresa não costumam contemplar os funcionários das empresas terceirizadas. Estas costumam realizar seus próprios eventos. Porém, em casos especiais, como número reduzido de funcionários em uma determinada turma ou área, os funcionários da Albras chamam terceirizados para compor as equipes;

No que diz respeito aos rendimentos, os terceirizados entrevistados que trabalham nas áreas de redução e fundição revelaram ganhar entre $\mathrm{R} \$ 600,00$ e R\$ 850,00. Já os funcionários diretos da Albras entrevistados ganham em média R\$1.500,00 (operadores de produção). Mais do que os salários, o ponto mais enfatizado, pelos dois grupos, é o conjunto de benefícios oferecido pela empresa aos seus trabalhadores:

a) Auxílio-doença/acidente; auxílio-funeral; estabilidade provisória-maternidade desde a confirmação à empresa de gravidez até 90 dias após o término da licença maternidade; estabilidade provisória - aposentadoria após cinco anos de serviço efetivamente prestado à Albras, garan- 
tida ao empregado a partir de 24 meses anteriores à data em que comprovadamente passe a fazer jus à aposentadoria integral da Previdência Social; seguro de vida em grupo e acidentes pessoais; vale alimentação ou vale refeição no valor total de $\mathrm{R} \$ 337,90$ com desconto mensal 0,7\% sobre o salário-base; descontos de percentual máximo de 3\% do salário-base do empregado que optar pelo benefício do vale-transporte ou passagens correspondentes ao valor do vale, adiantados pela empresa no início de cada mês, em substituição aos $6 \%$ previstos na legislação.

b) Assistência médica e odontológica, sendo que em tratamentos de pequeno risco o empregado participa com $20 \%$ do valor de qualquer atendimento, inclusive consulta de acordo com o valor da tabela AMB (Associação Médica Brasileira), cabendo à empresa 80\%. Nos tratamentos de grande risco, o empregado arca com 5\% e a empresa com 95\%.

c) Creche para filhos de funcionários que tenham até 36 meses de idade;

d) Subsídios nas mensalidades escolares de dependentes menores de 18 anos nos ensino fundamental a médio (regular e supletivo), independente do local da matrícula. Integral para os filhos de funcionários com salário base de até $\mathrm{R} \$ 1.957,00$. No caso de funcionários que ganhem acima deste valor, a empresa paga a mensalidade escolar mediante desconto da importância de $\mathrm{R} \$ 20,00$ por aluno/mês, até o limite mensal de R\$40,00. Também são concedidas 150 bolsas de material escolar para os dependentes dos funcionários de menor renda;

e) 60 bolsas escolares disponíveis para os funcionários que estejam cursando o 30 Grau, mediante reembolso parcial de até $R \$ 193,50$. Sendo que os critérios de concessão são empregados matriculados em cursos afins às carreiras da Albras e com menores salários.

Como se pode imaginar, toda essa rede de proteção social disponibilizada aos trabalhadores diretos, via acordo coletivo, não é acessada 
pelos trabalhadores terceirizados. A destituição dessa rede coloca os terceirizados numa situação de responsabilização total pelo provimento de todo o conjunto dos benefícios acima elencados. Deste modo, não fica difícil perceber que agregando ao salário esse conjunto de benefícios, a sensação de segurança social dos trabalhadores diretos da Albras é significativamente maior que a dos terceirizados. Essa situação configura uma sensação de insegurança social e ontológica para todos aqueles que por ela são afetados. Até porque, como lembra Castel:

A insegurança social não alimenta somente a pobreza. Ela age como um princípio de desmoralização, de dissociação social à maneira de um vírus que impregna a vida cotidiana. Dissolve os laços sociais e mina as estruturas psíquicas dos indivíduos. Ela induz uma "corrosão do caráter" para retomar uma expressão que Richard Sennett emprega num outro contexto. Estar em numa insegurança permanente é não poder nem controlar o presente, nem antecipar positivamente o futuro (2005, p. 31).

Isto fica claro na figuração existente entre os dois grupos de trabalhadores, pois as sensações de incerteza e insegurança são recorrentes nas falas dos terceirizados:

Ah, se eu pudesse ter um emprego diferente não estaria trabalhando assim, prestando serviço para outra empresa, tinha o meu próprio negócio. (trabalhador terceirizado, auxiliar de supervisor na área de redução, 38 anos, casado, primeiro grau completo e residente em Abaetetuba).

Não, não me sinto seguro. Pra falar a verdade estou com medo de ficar na empresa (terceirizada) e perder o tempo que eu já tenho nela, perder tudo. Ela é uma empresa muito ruim, atrasa o nosso pagamento e tem muita gente que já saiu e jogou na justiça e está recebendo parcelado, aí eu tenho medo do dia que eu sair, pois cada vez mais ela piora. Tenho medo do dia que eu sair e jogar tudo isso fora, esse tempo que eu tenho aqui (trabalhador terceirizado, ope- 
rador de cintagem ${ }^{9}$ na área de fundição, 24 anos, solteiro, primeiro grau incompleto e residente em Barcarena na ocupação Beira Rio).

Nesse sentido, a figuração se completa quando consideramos a fala de trabalhadores diretos da Albras que estão mais distantes do tempo de aposentadoria, pois alguns destes dizem o seguinte sobre a possibilidade de trabalhar como terceirizados:

Eu acho que eu não, se fosse um caso de terceirizar a área lá dificilmente eu ficaria, particularmente falando, porque como eu to te falando, as terceirizadas não tem nenhum tipo de comparação com as empresas que contratam a terceirizada, diminuiria muito em benefícios e outras coisas mais (operador de produção, 30 anos, casado, uma filha, segundo grau completo, trabalha há seis anos na empresa e reside em Vila dos Cabanos).

Dependeria muito do contrato, até que ponto seria rentável pra mim. Porque se você pegar, vamos dizer que transformasse numa cooperativa, e a cooperativa me desse todos os benefícios que eu tenho hoje, eu toparia que o nosso trabaIho fosse terceirizado pra empresa, pois aí nós formaríamos uma cooperativa, onde manteria todos os benefícios que nós temos né, e faria a mesma função, aí seria justo. Agora sair de um plano com ótimos benefícios pra ir só por salário, fica mais complicado, porque se não souber administrar esse salário, quando chegar lá na frente, vai se ver no fundo do poço (operador de produção, 32 anos, casado, segundo grau completo, dois filhos, trabalha há 11 anos na empresa e reside em Vila dos Cabanos).

Hoje, pelo meu grau de instrução e pelo o que eu estou trabalhando, se a empresa terceirizasse e me contratasse pra ser terceirizado não seria interessante pra mim. Porque, além do salário, lógico, os benefícios são muito bons pra

9 O operador de cintagem é o trabalhador que realiza a ação de "cintar" os lingontes de alumínio, quer dizer, depois da empilhadeira organizar os lingotes no pátio destinado à armazenagem, cada operador de cintagem separa uma quantidade de quatro a seis lingotes e "amarra" com uma cinta, ele "cinta" os lingotes para que eles sejam organizados em lotes, um sobre o outro. 
gente, porque se isso falta, lá pra frente vai ter problema, porque os benefícios ajudam muito, por isso não é viável pra mim hoje (operador de produção, 22 anos, solteiro, trabalha na empresa há dois anos e reside em Vila dos Cabanos).

Se na percepção dos trabalhadores diretos se nota certa aversão à possibilidade de trabalhar como terceirizado, isto decorre da não proximidade da aposentadoria, já que, para aqueles que estão mais próximos desta, o trabalho terceirizado não é pensado como algo tão indesejável. A condição de antiguidade na empresa lhes dá uma sensação de maior segurança, mesmo que não plenamente justificada, vide os programas de reestruturação já realizados no decorrer dos últimos 20 anos. Assim, a proximidade da aposentadoria os faz perceber o trabalho terceirizado como uma oportunidade de um ganho adicional. Por outro lado, na fala dos terceirizados é possível notar certa resignação à condição de incerteza que caracteriza a situação a qual estão sujeitos. Nesse sentido, os dois depoimentos anteriores são bem ilustrativos, pois exprimem tanto a assunção ao discurso do empresário de si mesmo, tão em voga em tempos de flexibilização, quanto o medo de se ver desprotegido socialmente pela condição de desemprego criada por essa mesma lógica.

Dessa forma, a figuração identitária entre trabalhadores diretos e terceirizados tem como seu fundamento mais visível a rede de proteção social que a empresa disponibiliza aos seus empregados e que as prestadoras de serviços não oferecem. Esta situação instala percepções distintas sobre a condição de terceirizado, porém percepções que se baseiam na mesma oposição binária: segurança/insegurança. A sensação mais ou menos intensa de um desses elementos é o que torna possível planejar a vida presente e a vida futura, assim como também se sentir plenamente integrado em um projeto comum de coletividade. No caso em questão, isso corresponde ao sentimento de pertença decorrente da rede de sociabilidade interna e externa que ser funcionário da Albras oportuniza. Não por outra razão, Castel nos fala que em situações como estas, 
A insegurança social faz da vida um combate pela sobrevivência dia após dia, cuja saída é cada vez mais incerta. Poderíamos falar de desassociação social (o contrário de coesão social) para dar um nome a este tipo de situação, como a dos proletários do século XIX, condenados a uma precariedade permanente, que é também uma insegurança permanente por falta de ter o mínimo controle sobre o que Ihes acontece (2005, p. 31).

Nessa linha, Bourdieu (1998) advoga que as estratégias de precarização decorrentes da flexibilização produtiva recaem tanto sobre os terceirizados quanto sobre os trabalhadores diretos. Entre os terceirizados elas atuam de forma direta por meio da sua desmobilização enquanto grupo social, já entre os trabalhadores diretos elas atuam de forma indireta por meio da imposição do medo contínuo de que a qualquer momento poderão assolá-los. A figuração existente entre os trabalhadores terceirizados e diretos da Albras caracteriza bem essa situação, vide os processos de reestruturação produtiva e a implementação de modelos gerenciais inspirados na experiência fabril japonesa. Dessa forma, a condição de terceirizado passa a ser entendida como uma decorrência da atual configuração do capitalismo global, como se esta fosse mais uma fatalidade econômica do que um produto de uma vontade política. Assim:

A empresa "flexível" explora, de certa forma deliberadamente, uma situação de insegurança que ela contribui para reforçar: ela procura baixar os custos, mas também tornar possivel essa baixa, pondo o trabalhador em risco permanente de perder seu trabalho (BOURDIEU, 1998, p. 123).

Outro ponto a ser destacado é que todos os terceirizados entrevistados que não foram funcionários da Albras estão cientes de que com a qualificação que possuem eles não têm chances de ingressar no quadro funcional da empresa. Os trabalhadores terceirizados residentes em Abaetetuba externaram a dificuldade de se obter qualificação técnica nes- 
te município devido a não existência de uma escola técnica, como, por exemplo, a escola do Senai - Serviço Nacional de Aprendizagem Industrial - existente em Barcarena. Além disso, eles revelaram também falta de disponibilidade de tempo e desânimo em voltar a estudar para obter o diploma do $2^{\circ}$ grau, assim como também dificuldade de arcar com as despesas dos cursos de qualificação necessários. O que não ocorre com os trabalhadores diretos, pois estes têm acesso aos cursos de atualização custeados pela empresa. Todavia, alguns terceirizados ainda alimentam o desejo de trabalhar na Albras, apesar de saberem das dificuldades para conseguir isto, principalmente devido ao grau de educação formal que possuem se colocar como um impeditivo, já que a empresa exige que no mínimo se tenha o $2^{\circ}$ grau completo para ingressar em seu corpo funcional. Apesar disso, nas suas falas é possível perceber certa incorporação do discurso da responsabilização dos indivíduos pela sua condição de empregabilidade (CASTEL, 2003). Vide os seguintes depoimentos:

Eu tenho a vontade de que um dia dê certo pra eu chegar lá na Albras, mas pra eu entrar lá eu tenho que fazer os cursos, né, estudar um pouco mais, porque a minha escolaridade não é suficiente, aí daqui pra frente agente vai ver como é que dá... (Trabalhador terceirizado, 38 anos, casado, primeiro grau completo, auxiliar de supervisor na área de redução e residente em Abaetetuba).

[...] ainda não tenho $2^{\circ}$ grau completo, mas eu acho que se eu tivesse, eu já estaria na Albras, com certeza. Eu tenho um tio que trabalhou lá e hoje trabalha na Alunorte, ele sempre fala para eu estudar, que ele ia conseguir para mim e agora ele saiu da Albras e foi para a Alunorte. Estou querendo continuar estudando. Ontem mesmo falei com ele, ele falou que é para eu correr atrás que ele arranja uma vaga para mim na Alunorte (trabalhador terceirizado, 24 anos, solteiro, primeiro grau incompleto, operador de cintagem na área de fundição e residente em Barcarena na ocupação Beira Rio). 
No contexto da globalização de inspiração neoliberal, o Estado é percebido como fragilizado para a tarefa de promover o acesso aos bens públicos, e aqui se entenda também condições de sustentar qualquer rede de proteção social baseada em direitos trabalhistas e previdenciários. Porém, é preciso perceber que tal situação corresponde muito mais a uma construção discursiva que lhe imputa essa condição do que propriamente a impossibilidades que lhes sejam inerentes. Todavia, como nos lembra Bourdieu, esse discurso não possui a neutralidade alegada por seus defensores, até porque sua origem é socialmente bem definida, qual seja: a moral americana da poupança e seu ascetismo econômico que estão no cerne da noção de self-help. Além do que, essa lógica sustenta-se em alguns postulados distorcidos da teoria econômica:

[...] o primeiro postulado é que a economia é um domínio à parte, separado do mundo social, governado por leis naturais, universais, que os governos não devem contrariar. $O$ segundo postulado diz que o mercado é a instância capaz de organizar de forma ótima as relações sociais, as trocas, a produção, etc., e também de garantir uma distribuição eqüitativa. Faz-se uma equação entre mercado e democracia. O terceiro postulado afirma que a globalização exige a redução das despesas do Estado, a diminuição das despesas sociais - ou seja, o retorno ao laissez faire - e a supressão de tudo o que possa turvar a lógica pura do mercado. Os direitos sociais em matéria de emprego, previdência social, são vistos como onerosos e disfuncionais. Há também o discurso segundo o qual o welfare state [estado do bem estar social] estimula a preguiça, velho discurso americano ligado à tradição calvinista do self-help ['se virar' por conta própria](...) Nesse momento, no mundo inteiro só se fala em responsabilidade. Evidentemente o axioma principal é que o pobre é responsável por sua pobreza. Em meu jargão, digo que isso é uma sociodicéia, ou seja, uma narrativa que tem por função justificar a sociedade tal como ela é (2002, p. 26). 
A incorporação dessa narrativa conduz à crença de que a transformação de nossas condições de vida é uma tarefa que compete exclusivamente a nós mesmos, de modo isolado ou agregado aos que se encontrem na mesma situação, vide o crescimento das cooperativas como alternativa ao desemprego. Aqui, o problema não vem a ser como o atual estágio de acumulação capitalista se configura, mas sim como disseminar o espírito empreendedor para aqueles sobre os quais a destituição do acesso a um emprego socialmente protegido se impõe. Alicerçada em uma ideologia da competência, essa narrativa cria um cenário propício para a disseminação da ideia do indivíduo como empreendedor de si mesmo, ou seja, como responsável pela sua condição de empregabilidade. Deste modo, o precário se naturaliza à medida que esse discurso é assimilado pela sociedade como uma resposta adequada para o desemprego estrutural.

Nessa linha discursiva, qualquer alternativa que não se dê nesses termos não é tida como viável, pois a criação de empregos com rede de proteção social é tida como indesejável devido ao aumento de custos que gera para o mercado. Também ao Estado não seria mais possível fazê-lo, pois o crescimento do déficit público se tornaria um fator de inviabilização do caráter gerencial que este deve assumir. Nesse cenário, o que parece restar, para um número cada vez maior de pessoas, é a resignação ante a condição de excluído permanente do acesso a um emprego como expressão de direitos sociais.

\section{Considerações finais}

Na maioria dos casos, o processo de terceirização tem assumido a forma de trabalho precário, pois normalmente não está inserido na rede de proteção social que caracterizou o período taylorista-fordista. Dessa forma, o que se testemunha é o surgimento de uma condição de vulnera- 
bilidade tanto nas condições objetivas de vida dos trabalhadores, quando da percepção subjetiva que estes fazem de si mesmos a partir da esfera do trabalho. Assim, a sociedade passa a conviver não apenas com a insegurança e a fragilidade da relação salarial, mas também passa a assistir o desmoronamento dos princípios reguladores e fundadores de coesão do sistema de vida social (CASTEL, 2003; SENNETT, 1999). O caso dos trabalhadores terceirizados que prestam serviços à Albras evidencia esta situação, pois a destituição do acesso à rede de proteção social que é oferecida aos trabalhadores diretos não precariza apenas a sociabilidade nos limites circunscritos da planta industrial, mas se estende por todos os espaços de sociabilidade fora dela.

A figuração social existente entre os dois grupos caracteriza um quadro no qual podemos notar que novas hierarquias sociais são criadas dentro e fora das empresas que adotam o processo de terceirização como um dos pilares de sustentação de organizações mais horizontalizadas e menos burocráticas. Em outras palavras, a eliminação de hierarquias formais não conduz necessariamente à eliminação de hierarquias de fato. Se antes tínhamos hierarquias formalizadas dentro das fábricas, hoje, com a flexibilização, elas se apresentam de maneira informal e velada, porém certamente sentidas nas esferas de sociabilidade daqueles que foram atingidos pelo processo de terceirização. Nesse ponto, pensar essas novas hierarquias sociais é ver nelas a configuração de uma situação em que a distinção entre estabelecidos e outsiders se faz presente na situação dos trabalhadores diretos e terceirizados da Albras. Em outras palavras, a inserção dos trabalhadores diretos, não apenas na rede de proteção social oferecida pela empresa, mas também nas esferas de sociabilidade existentes em Vila dos Cabanos Ihes confere uma posição privilegiada ante os terceirizados no que diz respeito à figuração social entre os dois grupos. 
Assim, devido à incorporação da cultura organizacional da empresa por parte dos trabalhadores diretos, o que temos é uma propensão para um discurso de naturalização da condição de terceirizado como decorrência do aumento dos níveis de responsabilização individual pela adaptação às novas situações de trabalho exigidas no "mundo globalizado". Até porque, se por um lado temos um constrangimento apiedado da parte dos trabalhadores diretos ante a condição dos terceirizados, por outro temos uma resignação quase que generalizada em ambos os grupos a tal condição, como se esta realmente fosse uma condição natural explicitada pelo atual estágio de acumulação capitalista e não uma construção social deste; condição com a qual, fatalisticamente, o que parece restar é a resignação, e nos casos dos trabalhadores diretos, torcer para que ela não incida sobre suas vidas.

\section{The acknowledgment of the precarious social identity in the primary aluminum industry in the state of Pará, Brazil}

\section{Abstract}

This study intends to examine to what extent the outsourcing process in an industry of primary aluminum, in the city of Barcarena, Pará, results in differentiation in the social identities of direct and outsourced workers. Outsourced workers have a different status in the workplace, which excludes them from the benefits offered by the companies. As a result, society has to deal not only with the fragility of the wage relationship, but also with the collapse of the principles that regulate sociability among workers. The hypothesis is that the precarious statutes responsible for the conditions of outsourced workers are extended throughout their social lives, which gives them a distinct social identity. Fifteen interviews were conducted with each group of workers; two union leaders were also interviewed. Furthermore, the article examines the collective agreement between the direct workers and the company, and that company's yearly reports, since 2003.

Keywords: Flexible production. Outsourcing. Precariousness. Social identity. Albras (Alumínio Brasileiro S.A.). 


\section{Referências}

ANTUNES, Ricardo. Adeus ao trabalho? 10ª ed. São Paulo: Cortez, 2005. 200 p. . Os sentidos do trabalho: ensaio sobre a afirmação e a negação do trabalho. São Paulo: Boitempo, 1999. 258 p.

$\mathrm{BIHR}$, Alain. Da grande noite à alternativa: o movimento operário europeu em crise. 2ª ed. São Paulo: Boitempo. 1998.

BOURDIEU, Pierre. O poder simbólico. Rio de Janeiro: Bertrand Brasil, 1998a. $311 \mathrm{p}$.

. Contrafogos: táticas para enfrentar a invasão neoliberal. Rio de Janeiro: Jorge Zahar, 1998b. 151 p.

. Pierre Bourdieu entrevistado por Maria Andréa Loyola. Rio de Janeiro: EdUerj, 2002. 98 p.

CARMO, Eunápio Dutra do. Gestão do trabalho na indústria de alumínio Albras: noção de qualidade e seus interlocutores. Belém: NAEA/UFPA, 2000. 262 p.

CASTEL, Robert. As metamorfoses da questão social: uma crônica do salário. $4^{a} \underline{a}$ ed. Petrópolis: Vozes, 2003. 611 p. $95 \mathrm{p}$.

. A insegurança social: o que é ser protegido? Petrópolis: Vozes, 2005.

CASTELLS, Manuel. A sociedade em rede - A era da informação: economia, sociedade e cultura. 6a ed. São Paulo: Paz e Terra, 2002. 698 p.

CASTRO, Edna. Reestruturação produtiva e mercado de trabalho. Belém: Paper do NAEA n. 95. 1998. 20 p.

COCCO, Giuseppe. Trabalho e cidadania. 2ae ed. São Paulo: Cortez, 2001. 183 p.

CORIAT, Benjamin. Pensar pelo avesso: o modelo japonês de trabalho e organização.Rio de Janeiro: UFRJ / Revan, 1994. 209 p.

DRUCK, Maria da Graça. Terceirização: (des)fordizando a fábrica. São Paulo: Boitempo, 1999. $271 \mathrm{p}$.

ELIAS, Norbert; SCOTSON, John. Os estabelecidos e os outsiders. Rio de Janeiro: Jorge Zahar, 1990. 224 p.

EMPRESA DE PESQUISA ENERGÉTICA. Consumo industrial. In: MINISTÉRIO DE MINAS E ENERGIA, Mercado de Energia Elétrica 2006 - 2015. Empresa de Pesquisa Energética, Rio de Janeiro, 2005. p. 380. p. 43-93. 
GORZ, André. Adeus ao proletariado. Rio de Janeiro: Forense, 1987. 204 p. HABERMAS, Jürgen. "A Nova Intransparência". Novos Estudos Cebrap, São Paulo, n. 18, p. 103-114, set. 1990.

HARVEY, David. Condição pós-moderna. 13ạ ed. São Paulo: Loyola, 2004. 349 p. LEITE, Márcia de Paula. Modernização tecnológica e relações indústrias no Brasil: o quadro atual. In: GITAHY, Leda (Org.) Reestructuración productiva, trabajo y educación em América Latina. CHD-CENED/UNESCO-OREALC. Campinas, 1994. p. 297. p. 109-122.

LÔBO, Marco Aurélio Arbage. Estado e capital transnacional na Amazônia: o caso da ALBRÀS-ALUNORTE. Belém: NAEA/UFPA, 1996. 171 p.

KOVÁCS, Ilona. Empresa flexível: problemas sociais do pós-taylorismo. In SANTOS, Maria João et al. Globalizações: novos rumos do mundo do trabalho. Florianópolis/Lisboa: UFSC/Socius, 2001. 209 p.

MATTOSO, Jorge E. A desordem do trabalho. São Paulo: Scritta, 1995. 210 p.

NAHUM, João Santos. O uso do território em Barcarena: modernização e ações políticas conservadoras. 2006. 126 f. (Doutorado em Geografia) - Instituto de Geociências e Ciências Exatas Universidade Estadual Paulita, Rio Claro.

OFFE, Claus. Trabalho como categoria fundamental. In: OFFE, Claus (Org.). Trabalho e sociedade: problemas estruturais e perspectivas para o futuro da sociedade do trabalho. Biblioteca Tempo Universitário: Rio de Janeiro, 1989. 215 p. p.13-41.

OHNO, Taiichi. O sistema Toyota de produção: além da produção em larga escala. São Paulo: Bookman Companhia, 1997. 152 p.

PINTO, Lúcio Flávio. Mineração e desenvolvimento no sudeste do Pará: há mesmo? Disponível: www.adital.com.br. Acesso em: 13 mar. 2007.

PIORE, M; SABEL, L. The second industrial divide: possibilities for properity. New York: Basic Boocks Inc. Pub, 1986. 356 p.

RODRIGUES, Roberta Menezes. Vila dos Cabanos: o período de transição. Relações urbanas e perspectivas de gestão. 1998. 60 f. (Monografia de especialização) - Núcleo de Altos Estudos Amazônicos/ Universidade Federal do Pará, Belém.

RUAS, Roberto. Reestruturação socioeconômica, adaptação das empresas e gestão do trabalho. In: GITAHY, Leda (org.) Reestructuración productiva, trabajo y educación em América Latina. CHD-CENED/UNESCO-OREALC. Campinas. 297 p. p. 95-107.

SENNETT, Richard. A corrosão do caráter: consequências pessoais do trabalho no novo capitalismo. Rio de Janeiro/ São Paulo: Record, 1999. 204 p. 
TARSITANO NETO, Frederico. A divisão internacional do trabalho e a nova indústria do alumínio na Amazônia. In: CASTRO, Edna (org). Industrialização e grandes projetos: desorganização e reorganização do espaço. Belém: UFPA, 1995. 410 p. p. 71-87.

TRINDADE, José Raimundo Barreto. A metamorfose do trabalho na Amazônia: para além da Mineração Rio do Norte. Belém: NAEA/UFPA, 2001. 172 p.

ZARIFIAN, Philippe. Produtividade e novo modelo de organização. In: FORTES, J. . \& Soares, R.M.S.M. Padrões tecnológicos, trabalho e dinâmica espacial. Brasília: UNB, 1996. 234 p.p. 21-44.

Recebido: 01/04/2008

Aceite final: 24/07/2008 